\title{
An Establishment of Super Wi-Fi Environment in Ships Based on UHF System of TMS
}

\author{
Jungwoo Kim ${ }^{1}$ and Jooyoung Son ${ }^{2}$ \\ ${ }^{1}$ Department of Power Control \& Automation Design, Hyundai Heavy Industries Co., Ltd., \\ Ulsan, Korea. \\ [e-mail: kimjungwoo@hhi.co.kr] \\ ${ }^{2}$ Div. of Marine IT Engineering, Korea Maritime \& Ocean University, \\ Busan, Korea \\ [e-mail: mmlab@kmou.ac.kr] \\ *Corresponding author: Jooyoung Son
}

Received May 26, 2017; revised August 10, 2017; accepted November 19, 2017; published May 31, 2018

\begin{abstract}
Ships built today are larger in scale and feature more complex structures. The ever-evolving systems used on board a ship require vast amounts of data processing. In the future, with the advent of smart ships, unmanned ships and other next-generation ships, the volumes of data to be processed will continue to increase. Yet, to date, ship data has been processed using wired networks. Placed at fixed locations, the nodes on wired networks often fail to process data from mobile devices. Despite many attempts made to use Wi-Fi on ships just as on land to create wireless networks, Wi-Fi has hardly been available due to the complex metal structures of ships. Therefore, Wi-Fi on ships has been patchy as the ship-wide total Wi-Fi coverage has not properly implemented. A new ship-wide wireless network environment is part of the technology conducive to the shipbuilding industry. The wireless network environment should not only serve the purpose of communication but also be able to manage and control multiple features in real-time: fault diagnostics, tracking, accident prevention and safety management. To better understand the characteristics of wireless frequencies for ships, this paper tests the widely used TETRA, UHF and Wi-Fi and sheds light on the features, advantages and disadvantages of each technology in ship settings. The proposed deployment of a Super Wi-Fi network leveraging the legacy UHF system of TMS generates a ship-wide wireless network environment. The experimental findings corroborate the feasibility of the proposed ship-wide Super Wi-Fi network environment.
\end{abstract}

Keywords: Super Wi-Fi, UHF, Wi-Fi, Ships, TMS 


\section{Introduction}

$\mathbf{N}_{\text {etworks used on board ships can be classified into either wired and wireless networks or }}$ power line communications. The wired networks consist of pair cables, coaxial cables and fiber optic cables. These cables are directly connected to the spots or equipment where communication is required. The wireless network involves installing the $\mathrm{Wi}$-Fi access points (AP) to the wired network with intent to provide the Internet and Voice over Internet Protocol (VoIP) access on board a ship. However, the deployment of the Wi-Fi is limited to the accommodation area. Therefore, a great deal of APs would be required to expand the Wi-Fi coverage to the entire ship with the foregoing method. As such, Wi-Fi is seldom used because of its high deployment and maintenance costs and poor stability on ships. The power line communications method involves installing power cables to the ship.This has the advantage of reducing the installation cost because there is no need for additional network cables. However, power line communications are rarely used due to the security vulnerability and do not guarantee QoS.

Different telecommunication methods are available depending on the types of ship structure. As in Fig. 1, the ship's structure is largely classified into the top side (the exterior) areas and the hull side (interior) areas.

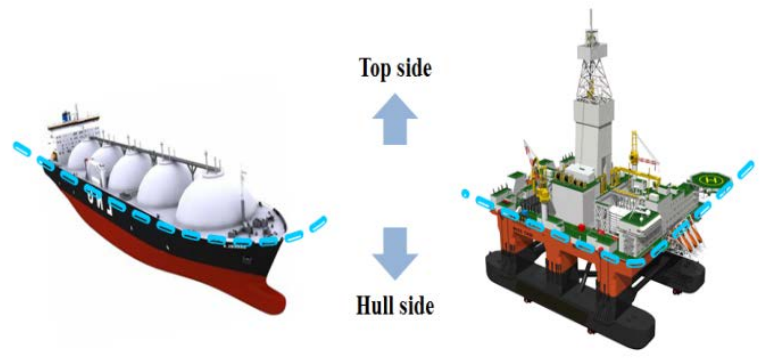

Fig. 1. Structure of ships

On the top side, several communication methods are used to stay connected with the entities on land and other ships. The Fleet Broadband (FB) and Very Small Aperture Terminal (VSAT) use satellites. The Very High Frequency (VHF) is used by long distance communication devices. The hull side is characterized by a lattice type structure detrimental to wireless networks, which is why wired networks are largely applied to the hull side. A ship may carry tens of kilometers to hundreds of kilometers of wired network cables, which translates into enormous deployment costs and limited scalability and alterability of such systems. Technologies for next-generation ships are expected to reduce operation costs. However, most new management techniques based on analysis merely add new desired functions to the existing systems. Accordingly, next-generation ships need more additional cables in order to meet the requirements of new functions. In case that next-generation ships continuously use only wired networks, technology development would be seriously limited due to the contraints in weight, space and other technological aspects. Using wireless networks on ships instead of wired networks can reduce not only ship-building time but also enhance the ease of use. 
There are three major ways of configuring a wireless network on ships. The first method is to use a commercial frequency band by a communication common carrier. Once the ship leaves the inshore area, the network for the commercial frequency becomes unavailable and the wireless network becomes inoperable. This method may not even be suitable for ships that stay inshore but sail across international borders. The second method is to build a private network that operates on a commercial frequency band.. This method has the disadvantages of high deployment costs and greater space required for the deployment. Also, once the ship travels outside the frequency band of the specified country, a frequency collision may occur. The third method is to build a private network that uses a shared frequency band. This is intended for $\mathrm{Wi}$-Fi that uses $2.4 \mathrm{GHz}$ and $5 \mathrm{GHz}$ frequency bands. This is the easiest method to deploy but the least efficient for the required cost since it has a radio propagation range from $10 \mathrm{~m}$ to $20 \mathrm{~m}$ around APs. To make matters worse, ships do not have many windows or ventilation opening compared to buildings on land, which poses more of a challenge for radio propagation. When wireless networks are deployed on ships, long ranges, low costs and the a ship-wide coverage with the same effect as a private network should be primarily considered. Among the systems currently in use on ships, the Ultra High Frequency (UHF) meets most of these requirements.

The UHF system is deployed for mostly wireless voice communications between operators on board a ship. This system uses the $400 \mathrm{MHz}$ frequency band. It has good bending and a long transmission distance that makes the communications possible across most parts of the ship with portable radio devices and a minimal number of antennas. In the future, UHF systems will be classified as mandatory systems even for the Telecommunication Management System (TMS), which is expected to control telecom systems on ships [1]. There are the Super Wi-Fi and the TErrestrial Trunked Radio (TETRA), which use a similar frequency band to UHF. The Super Wi-Fi is a technology that uses TV white space to provide the wireless Internet service [2]. That is very similar to the conventional Wi-Fi in that routers and APs are deployed as part of building wireless networks. TETRA is the standard for mobile wireless communications developed by the European Telecommunications Standards Institute (ETSI), which enables voice and data transmissions [3]. TETRA has been installed at some offshore plants in place of UHF and used for voice and message transmission and reception [4].

The combination of UHF for voice communications with Super Wi-Fi for wireless data communications enables the implementation of a new wireless network environment meeting the communication needs on ships. Today, most large ships are fitted with UHF. Therefore, the resources of the UHF system may be leveraged for Super Wi-Fi, which could ensure the advantage of reduced costs, minimization of installation errors and rapid stabilization of the system. Also, when applying the UHF's coverage study technique in the design phase, quality can be further improved with less costs [5]. This paper proposes establishing a wireless network environment of Super Wi-Fi leveraging the legacy UHF system in operation on ships. The feasibility of the proposed method is proved through experiments, which indicate the new Super Wi-Fi environment covers the entire ship without any fringe areas or dead spots.

\section{Definition of Super Wi-Fi}

The Super Wi-Fi is defined as a Wireless Local Area Network (WLAN) in the Institute of Electrical and Electronics Engineers (IEEE) 802.11af standard and as a Wireless Regional Area Network (WRAN) in the IEEE 802.22 standard [6]. The Super Wi-Fi uses the frequency band for TV white space to provide the wireless Internet service like the conventional Wi-Fi. 
As shown in Table 1, Super Wi-Fi uses lower frequencies between $54 \mathrm{MHz}$ and $790 \mathrm{MHz}$ in comparison to Wi-Fi [7].

Table 1. Comparison between Super Wi-Fi and conventional Wi-Fi

\begin{tabular}{|c|c|c|c|c|c|c|c|c|}
\hline Specification & \multicolumn{7}{|c|}{ Conventional Wi-Fi(802.11) } & Super Wi-Fi \\
\hline \hline Standard & - & $\mathrm{a}$ & $\mathrm{b}$ & $\mathrm{g}$ & $\mathrm{n}$ & $\mathrm{ac}$ & $\mathrm{ad}$ & $802.11 \mathrm{af}$ \\
\hline Frequency band & $2.4 \mathrm{GHz}$ & $5 \mathrm{GHz}$ & $2.4 \mathrm{GHz}$ & $2.4 \mathrm{GHz}$ & $\begin{array}{c}2.4 \mathrm{GHz}, \\
5 \mathrm{GHz}\end{array}$ & $5 \mathrm{GHz}$ & $60 \mathrm{GHz}$ & $\begin{array}{c}54 \mathrm{MHz} 698 \mathrm{MHz} \\
\text { (in USA) } \\
470 \mathrm{MHz} 790 \mathrm{MHz} \\
\text { (in Europe) }\end{array}$ \\
\hline Bandwidth & $20 \mathrm{MHz}$ & $22 \mathrm{MHz}$ & $21 \mathrm{MHz}$ & $23 \mathrm{MHz}$ & $\begin{array}{c}20 \sim \\
40 \mathrm{MHz}\end{array}$ & $\begin{array}{c}20 \sim \\
160 \mathrm{MHz}\end{array}$ & $2.16 \mathrm{GHz}$ & $6 \sim 8 \mathrm{MHz}$ \\
\hline Range & $20 \mathrm{~m}$ & $35 \mathrm{~m}$ & $35 \mathrm{~m}$ & $70 \mathrm{~m}$ & $70 \mathrm{~m}$ & $35 \mathrm{~m}$ & $10 \mathrm{~m}$ & $400 \mathrm{~m} \sim 1 \mathrm{Km}$ \\
\hline $\begin{array}{c}\text { Maximum Data } \\
\text { Rate }\end{array}$ & $2 \mathrm{Mbps}$ & $54 \mathrm{Mbps}$ & $11 \mathrm{Mbps}$ & $54 \mathrm{Mbps}$ & $600 \mathrm{Mbps}$ & $6.93 \mathrm{Gbps}$ & $6.76 \mathrm{Gbps}$ & $26.7 \mathrm{Mbps}$ \\
\hline
\end{tabular}

The Super Wi-Fi signals travel over longer distances, four times greater than those of the conventional Wi-Fi, with nine times the penetration through walls and obstacles, and 16 times greater the area covered [8]. The architecture of the Super Wi-Fi as defined in 802.11af is shown in Fig. 2 [2][9].

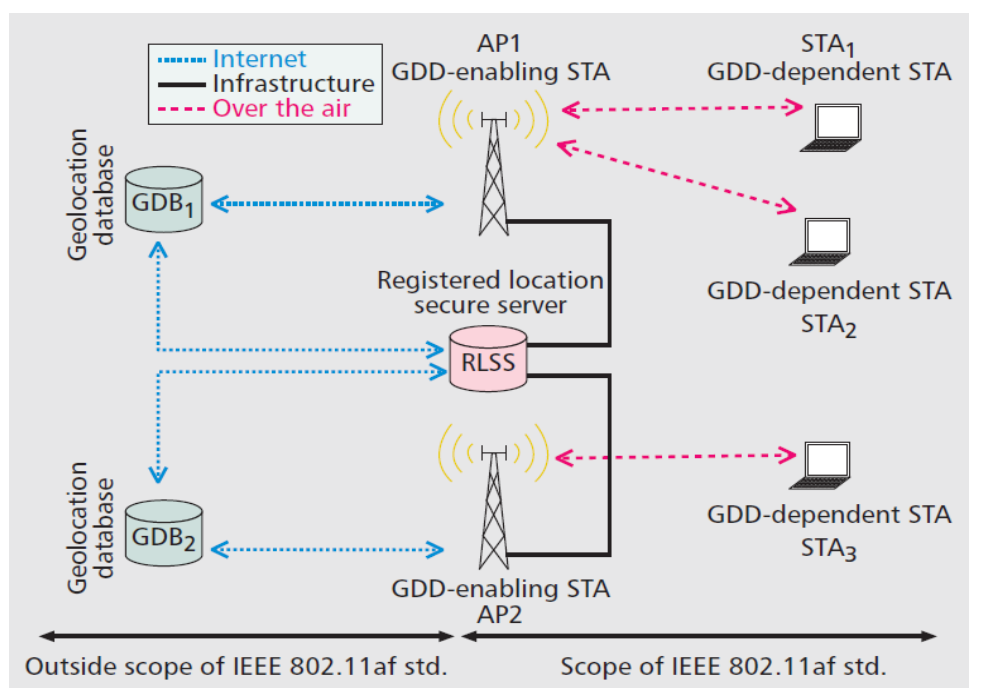

Fig. 2. TVWS network example including all 802.11af architecture entities

The standards include Geolocation Database Dependent enabling station (GDD-enabling STA), Registered Location Secure Server (RLSS), and Geolocation Database Dependent dependent station (GDD-dependent STA). Communications between Geolocation Database (GDB) and high level entities (RLSS and GDD-enabling STA) are excluded from the range of 802.11af. RLSS and GDD-enabling STA utilize the white space available for the Internet. RLSS communicates with the GDD-enabling STA by means of the infrastructure and can only operate bidirectionally. GDD-dependent STA provides over-the-air communication with GDD-enabled STA within the TV white spaces (TVWS) band or other Industry Science Medical (ISM) bands. 
Fig. 3 shows a schematic diagram of Super Wi-Fi based on Fig. 2. GDB has an available TVWS(TV White Space). The base station provides its location information to GDB. GDB provides the base station with available TVWS channel information. The base station selects the operating channel to initiate Super Wi-Fi service among the available TV channels and initiates Super Wi-Fi service via the AP.

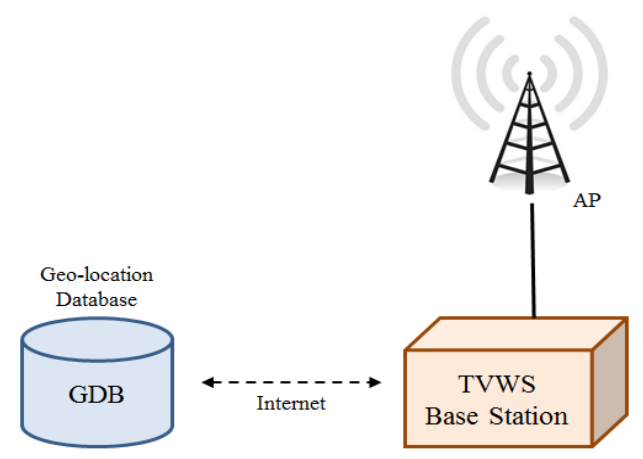

Fig. 3. Schematic diagram of Super Wi-Fi

The structure of Super Wi-Fi is similar to that of existing Wi-Fi except for the GDB. Due to the nature of Super Wi-Fi, GDB is required to use unlicensed frequency bands. The frequencies of ships at sea will not overlap with the broadcast frequencies by terrestrial broadcasters. Therefore, the operator will seldom need to return TV white space. In the instance where a ship is positioned at an offshore location, the GDB will register the frequency to the area. If the ship nears a specific area, the GDB automatically will notify the uninterrupted frequency band to the base station, which will in turn change its frequency. By this way, the ship can use Super Wi-Fi without restrictions on the frequency band whether at sail or at anchor.

\section{Definition of UHF System on Ships}

The UHF system is not a mandatory deployment according to the International Convention for the Safety of Life at Sea (SOLAS) [10-13]. But the UHF is suitable for communications on ships because long distance communications are possible despite complex and narrow structures on ships. Ships use the UHF frequency band of $450 \mathrm{MHz}$ to $470 \mathrm{MHz}$ allocated to onboard vessel communication by the International Telecommunication Union Radiocommunication Sector (ITU-R) M.1174-2 [14]. The VHF uses the frequency band of $156 \mathrm{MHz}$ to $174 \mathrm{MHz}$ for communication among ships and on shore [15].

The UHF system consists of base stations, repeaters, antennas and portable radios. Base stations and repeaters use duplex frequencies, whereas portable radios use simplex frequencies. The operation sequence is as follows: A portable radio transmits a Tx signal to a repeater, which receives the signal through an antenna installed around it. The repeater amplifies the received signal and transmits it back through the antenna. Portable radios in stand-by mode at the same frequency may receive the signal [5].

The UHF system on ships shown in Fig. 4 uses a whip antenna for outdoor areas, while spot and leaky antennas for indoor areas. 


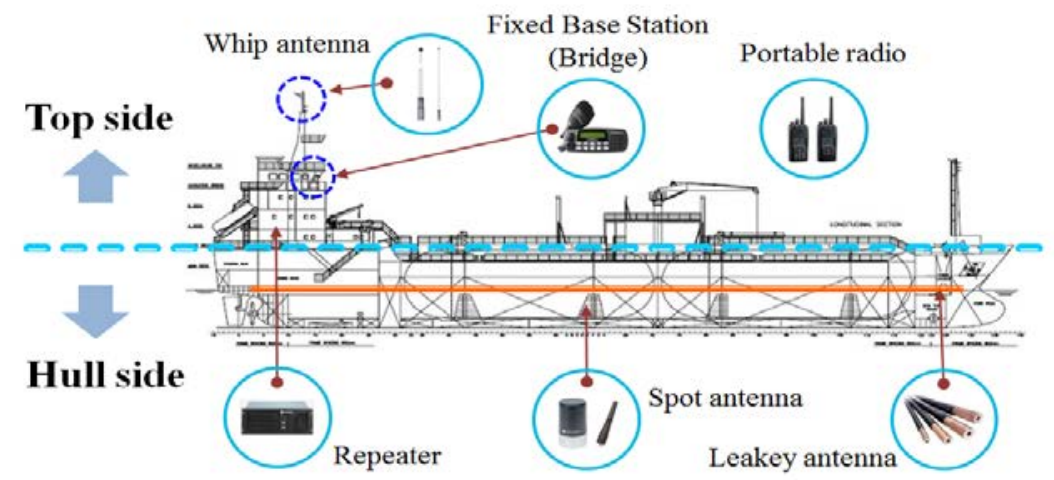

Fig. 4. Installation of UHF system on ships

The deployment of the UHF antennas overrides anything else for the ship-wide communications. However, the locations of the UHF antennas vary with designers [16]. Factors controlling the propagation range of a UHF antenna on ships include materials of ships, complexity of ship structures and if it is sealed or not. Various combined factors may decide the performance of the UHF antenna in terms of fringe areas and dead spots. The coverage study performed during the design phase can figure out the quantities and the locations of UHF antennas optimal for the structure and environment of ships.

\section{Comparative Analysis of Radio Frequencies Used on Ships}

We analyzed TETRA, UHF and Wi-Fi that are the typical wireless communication systems used on board ships, as well as the frequency band for the Super Wi-Fi system proposed in this paper. Fig. 5 is a collection of frequency bands for TETRA, UHF, Super Wi-Fi and Wi-Fi assigned to each organization or country.

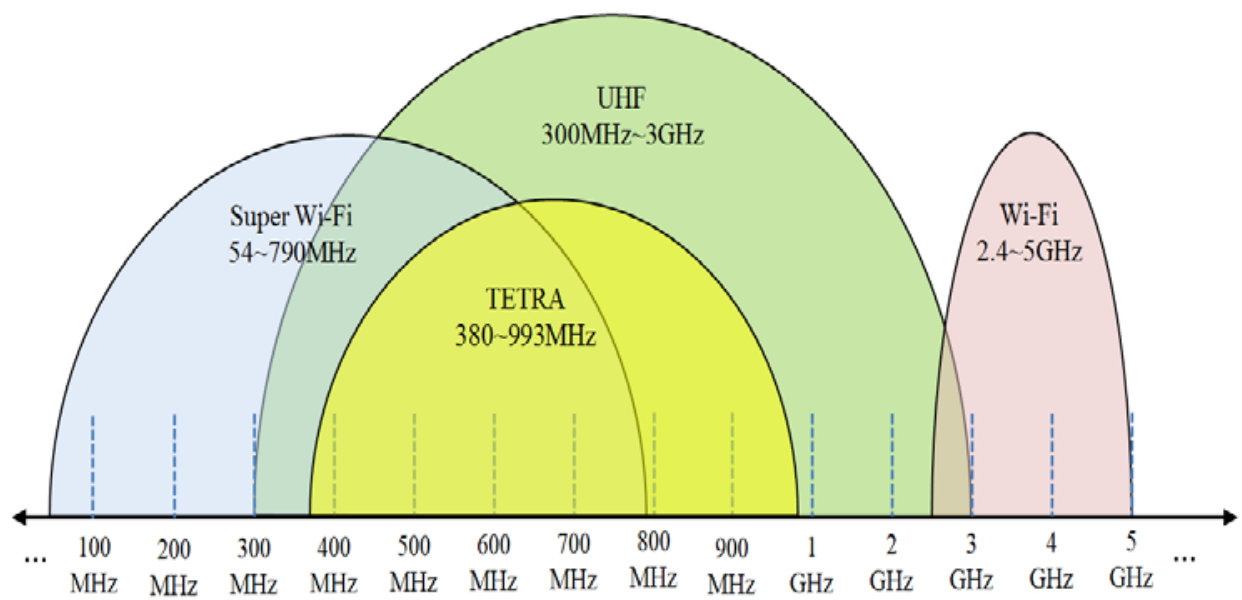

Fig. 5. Comparison of frequency bands

As shown in Fig. 5, the coverage study results of a wide frequency band overlap with the margin of error increasing. It is necessary to split the frequency bands of the systems that makes them suitable for ships in terms of the propagation range and characteristics. Likewise, 
the frequency band of each system is redefined through the following steps: First, a frequency band should be confirmed to be allocated for use on ships is in place. Second, it should be confirmed that the frequency bands that are primarily allocated to ships are in place. Some differences may exist depending on the country and waters that ships are sailing in. Third, there should be no overlap between the frequency bands of TETRA, UHF, Super Wi-Fi and Wi-Fi. Fourth, it should be confirmed that the frequency band can generate the maximum data rate for the allocated frequency band. Finally, there should be commercial products in place that support frequency bands.

The coverage experiments were conducted for the systems. Information of commercial communication devices operating on the above systems was used to set up the test environments. Structures and configurations of onboard actual ships were fully considered. Through this process, a coverage study was also performed on the frequency band redefined for the systems onboard ships, which indicated the similarities and characteristics between UHF and Super Wi-Fi.

\subsection{Analysis of Frequency Bands}

TETRA's communication method is similar to that of the UHF using fixed base stations and portable radios. But it is possible to exchange point-to-multipoint communication and data as with wireless internet. TETRA supports the data rate of 7.2Kbps per channel and is suitable for short data service [3][17]. The ETSI defines the TETRA frequency bands to be between $380 \mathrm{MHz}$ and $470 \mathrm{MHz}$ and between $870 \mathrm{MHz}$ and $993 \mathrm{MHz}$ [18]. The total frequency band assigned to TETRA extends from $380 \mathrm{MHz}$ to $993 \mathrm{MHz}$ as shown in Fig. 5. The European Conference of Postal and Telecommunications Administrations (CEPT / SE) defines the frequency band of TETRA to be between $380 \mathrm{MHz}$ and $400 \mathrm{MHz}$ [19]. TETRA's frequency bands vary across countries. A majority of European countries have allocated the $380 \mathrm{MHz}$ to $400 \mathrm{MH}$ band to emergency services [20], e.g. $380 \mathrm{MHz}$ to $385 \mathrm{MHz}, 390 \mathrm{MHz}$ to $395 \mathrm{MHz}$ and $406 \mathrm{MHz}$ to $410 \mathrm{MHz}$ in Germany; (bandwidths from) $350 \mathrm{MHz}$ to $370 \mathrm{MHz}$ and $870 \mathrm{MHz}$ to $921 \mathrm{MHz}$ in Saudi Arabia; and (bandwidths from) $380 \mathrm{MHz}$ to $385 \mathrm{MHz}$ and $870 \mathrm{MHz}$ to $876 \mathrm{MHz}$ in Norway [21]. TETRA is a frequency band, where frequencies in the $380 \mathrm{MHz}$ to $470 \mathrm{MHz}$ band are allocated to and used by vessels in Europe. For comparative experiments, this paper redefines the TETRA frequency as the $380 \mathrm{MHz}$ to $430 \mathrm{MHz}$ band, which does not overlap the UHF band.

The International Telecommunication Union (ITU) and the IEEE designate the $300 \mathrm{MHz}$ to $3 \mathrm{GHz}$ and the $300 \mathrm{MHz}$ to $1 \mathrm{GHz}$ bands as the UHF bands, respectively [22]. The total frequencies designated for the UHF are in the range between $300 \mathrm{MHz}$ and $3 \mathrm{GHz}$ as shown in Fig. 5. Specific frequency bands allocated to the UHF vary across relevant purposes and countries. Australia allocates the $476 \mathrm{MHz}$ to $477 \mathrm{MHz}$ band to citizen band radio, while the United Kingdom allocates the $470 \mathrm{MHz}$ to $854 \mathrm{MHz}$ band to analog terrestrial TV channels [23][24]. The United States designates the $225 \mathrm{MHz}$ to $399.9 \mathrm{MHz}$ band as the critical military radio communication band, and the $2,400 \mathrm{MHz}$ to $2,483.5 \mathrm{MHz}$ band as the amateur, fixed and mobile band [25]. Among the UHF bands extending from $300 \mathrm{MHz}$ to $3 \mathrm{GHz}$, the $450 \mathrm{MHz}$ to $470 \mathrm{MHz}$ band is set aside for ships. In this paper, the UHF band from $450 \mathrm{MHz}$ to $470 \mathrm{MHz}$ is redefined for the comparative experiments. Super Wi-Fi is allocated the frequencies between $54 \mathrm{MHz}$ and $698 \mathrm{MHz}$ in the United States, whereas those between $470 \mathrm{MHz}$ and $790 \mathrm{MHz}$ in Europe. The total frequency band assigned to Super Wi-Fi is the $54 \mathrm{MHz}$ to $790 \mathrm{MHz}$ band as shown in Fig. 5 [2]. Wireless networks can allocate bandwidths to high frequency bands to obtain high data rates. On the other hand, the higher the frequency band, the more difficult it is 
to secure the same stability as with Wi-Fi. Therefore, Super Wi-Fi for the ship data wireless network requires both high data rates and good stability. In this paper, the Super Wi-Fi frequency band for the comparative experiments is redefined to range from $750 \mathrm{MHz}$ to $790 \mathrm{MHz}$.

Fig. 6 shows the frequency bands for TETRA, UHF, and Super Wi-Fi, which were redefined so as not to overlap.



Fig. 6. Redefined frequency bands for UHF, TETRA and Super Wi-Fi

\subsection{Coverage study of Frequency Bands used on Ships}

For this paper, a coverage study was performed using a 19,000 TEU scale container carrier as a model for analyzing each frequency band relative to an actual ship structure. The target signal strength and the target coverage that form the basis for the coverage study are outlined in Table 2 [5].

Table 2. Specific design requirements for ships

\begin{tabular}{|c|c|}
\hline Category & Requirement \\
\hline \hline Target signal strength & $\begin{array}{l}\text { Fringe area }: \leq-85 \mathrm{dBm} \\
\text { Dead spot }: \leq-100 \mathrm{dBm}\end{array}$ \\
\hline Target coverage & $95 \%$ \\
\hline
\end{tabular}

Target signal strength is expressed in decibel-milliwatt $(\mathrm{dBm})$. The receiver dynamic sensitivity of most portable radios is between $-110 \mathrm{dBm}$ and $-100 \mathrm{dBm}$ [26]. In order to secure the reliability of data transmission and reception for the entire ship, there should be no loss of data due to the fringe areas. Thus, the target signal strength and the target coverage are defined as $-85 \mathrm{dBm}$ or greater and $95 \%$ or higher, respectively, as shown in Table 2.

The coverage study was carried out as in Fig. 7, and repeated until it satisfied Table 2. Table 3 shows the detailed specification for the coverage study setting [27]. 


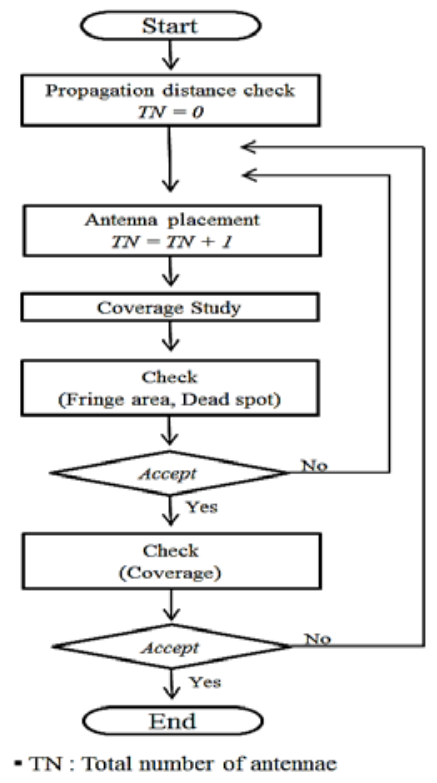

Fig. 7. A workflow of coverage study of frequency band

Table 3. Specification for coverage study

\begin{tabular}{|c|l|}
\hline \multicolumn{1}{|c|}{ Division } & \multicolumn{1}{c|}{ Specification } \\
\hline \hline H/W & $\begin{array}{l}\text { CPU : Intel(R) Core(TM) i5-3470 @ 3.20GHz } \\
\text { Memory : DDR3 4GB, Storage : SATA 500GB } \\
\text { OS : Microsoft Windows 7 Premium 32bit }\end{array}$ \\
\hline S/W & $\begin{array}{l}\text { iBwave Design Enterprise v 6.4.3 } \\
\text { 32-bit Edition }\end{array}$ \\
\hline
\end{tabular}

Table 4 shows the frequency bands for the coverage study, which was performed sequentially. First an antenna was placed at the same position on the ship prior to the first coverage study, where the frequency band's propagation range in the ship structure was identified. Finally, the final coverage study satisfying Table 2 was completed with a minimum number of antennas. It is important to achieve the ship-wide coverage. Still, it is more important to make sure no fringe areas or dead spots occur across the working areas.

Table 4. Defined List of frequency bands

\begin{tabular}{|c|c|c|}
\hline Seq. & System & Frequency Band \\
\hline \hline 1 & TETRA & $380 \mathrm{MHz} \sim 430 \mathrm{MHz}$ \\
\hline 3 & UHF & $450 \mathrm{MHz} \sim 470 \mathrm{MHz}$ \\
\hline 4 & Super Wi-Fi(802.11af) & $750 \mathrm{MHz} \sim 790 \mathrm{MHz}$ \\
\hline 5 & Wi-Fi(801.11b/g) & $2.4 \mathrm{GHz}$ \\
\hline 6 & Wi-Fi(802.11n) & $5 \mathrm{GHz}$ \\
\hline
\end{tabular}

Fig. 8 shows the result of the first coverage study for TETRA. The coverage is $82.6 \%$ when the signal strength is $-95 \mathrm{dBm}$, lower than $-85 \mathrm{dBm}$, which is the target signal strength of the 
fringe area. This numerical value meets neither the target signal strength nor the target coverage. It is possible to identify fringe areas lower than $-85 \mathrm{dBm}$ and dead spots lower than $-100 \mathrm{dBm}$ in the working areas of the bow and starboard side.
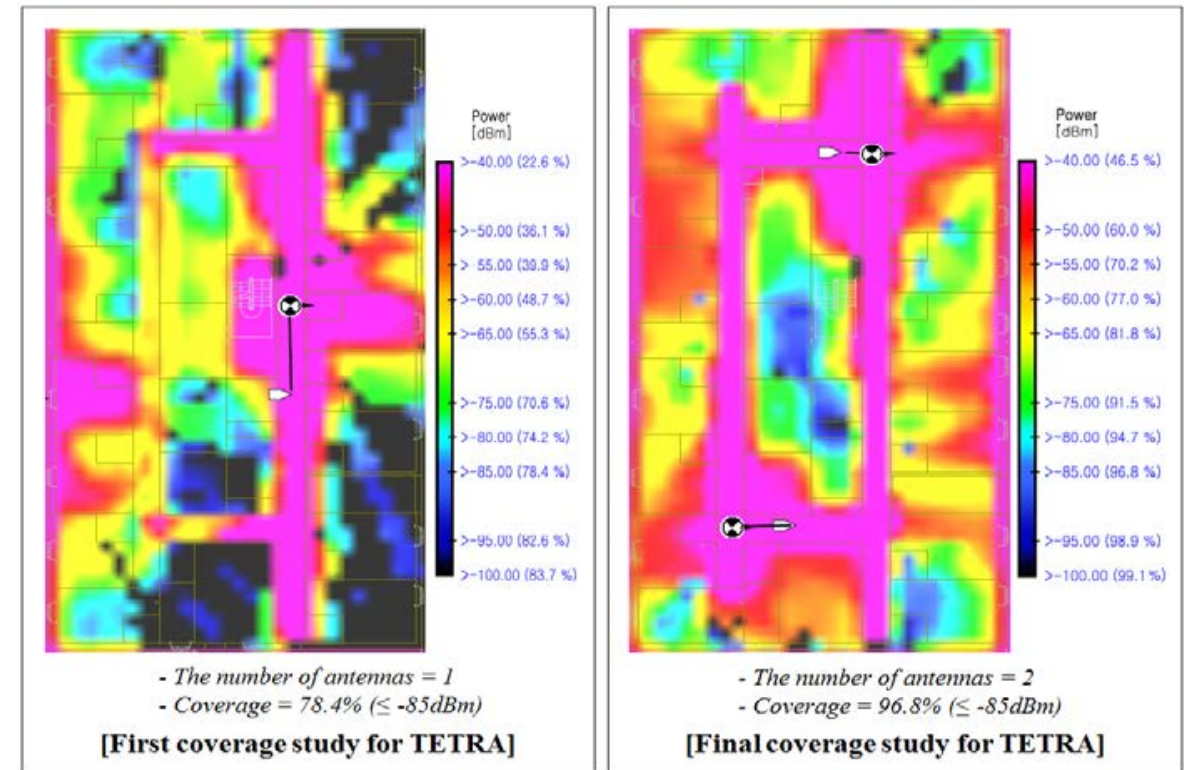

Fig. 8. Comparison of coverage study of TETRA

The final coverage study of TETRA was carried out by repeating the process of adding and repositioning the antenna. The coverage is $96.8 \%$ when the signal strength is higher than $-85 \mathrm{dBm}$, which is the target signal strength of the fringe area. This numerical value satisfies all the creteria in Table 2 with two TETRA antennas and can eliminate the fringe areas and dead spots in the working areas.


Fig. 9. Comparison of coverage study of UHF 
Fig. 9 shows the first UHF coverage study results. The coverage is $79.6 \%$ when the signal strength is $-95 \mathrm{dBm}$, lower than $-85 \mathrm{dBm}$, which is the target signal strength of the fringe area. The coverage performance is $4.7 \%$ lower than the first coverage study results of TETRA shown in Fig. 8.

This numerical value satisfies neither the target signal strength nor the target coverage in Table 2. It is possible to identify fringe areas lower than $-85 \mathrm{dBm}$ and dead spots lower than $-100 \mathrm{dBm}$ in the working areas of the bow and starboard side. In particular, fringe areas and dead spots in the starboard are distributed more widely than the first coverage of TETRA.

The final coverage study of UHF was carried out by repeating the process of adding and repositioning the antenna. The coverage in the final study is $95.6 \%$ when the signal strength is higher than -85dBm, which is the target signal strength of the fringe area. This numerical value satisfies all the creteria in Table 2 with two UHF antennas and can eliminate the fringe areas and dead spots in the working areas.

Fig. 10 shows the first Super Wi-Fi coverage study results. The coverage is $78.6 \%$ when the signal strength is $-95 \mathrm{dBm}$, lower than $-85 \mathrm{dBm}$, which is the target signal strength of the fringe area. The coverage performance is $9.7 \%$ and $5.2 \%$ lower than the first coverage study results of TETRA in Fig. 8 and UHF in Fig. 9, Respetively. This numerical value satisfies neither the target signal strength nor the target coverage in Table 2. It is possible to identify fringe areas lower than $-85 \mathrm{dBm}$ and dead spots lower than $-100 \mathrm{dBm}$ in the working areas of the bow, starboard side and port side. The fringe areas and dead spots that appeared on the port side were not observed in TETRA and UHF.

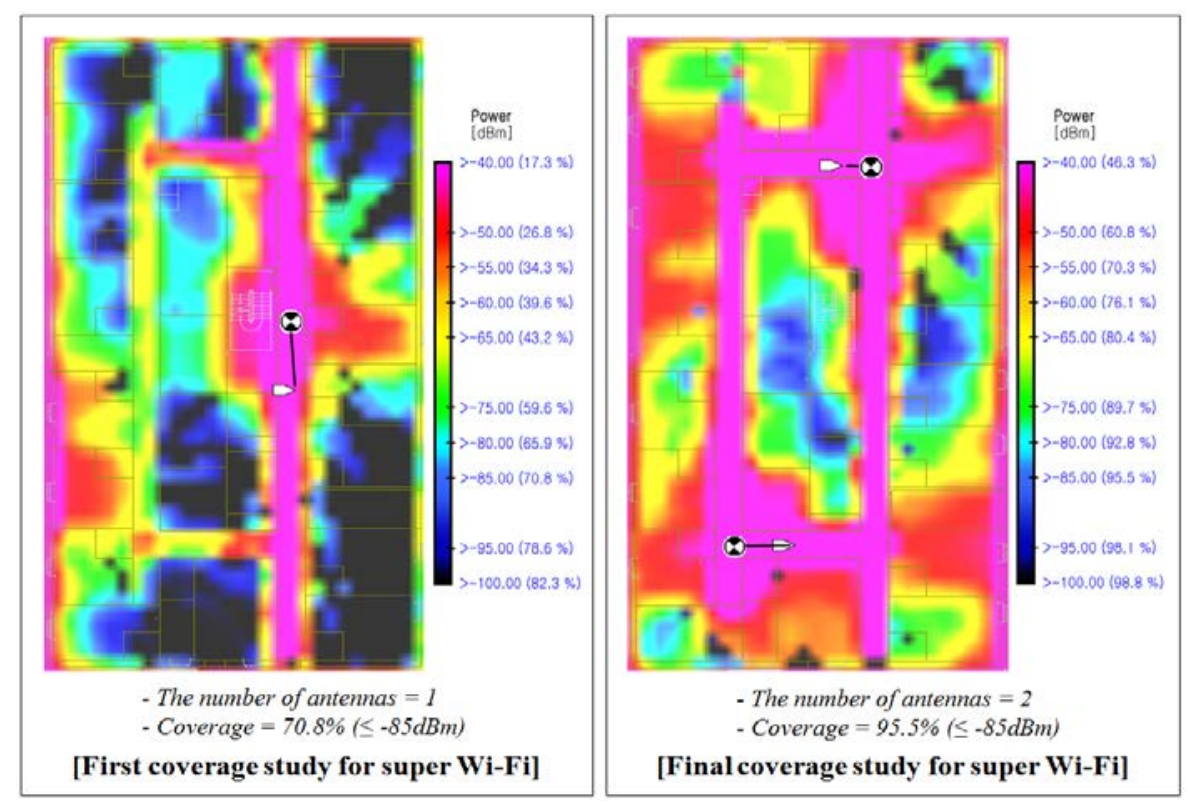

Fig. 10. Comparison of coverage study of Super Wi-Fi

The final coverage study of Super Wi-Fi was carried out by repeating the process of adding and repositioning the antenna. The coverage of the final study is $95.5 \%$ when the signal strength is higher than $-85 \mathrm{dBm}$, which is the target signal strength of the fringe area. This numerical value satisfies all the creteria in Table 2 with two Super Wi-Fi antennas and can eliminate the fringe areas and dead spots in the working areas. 
Fig. 11 shows the first $\mathrm{Wi}-\mathrm{Fi}(2.4 \mathrm{GHz})$ coverage study results. The coverage is $21.5 \%$ when the signal strength is $-85 \mathrm{dBm}$, which is the target signal strength of the fringe area. There is a significant difference in the first coverage study results between TETRA, UHF, and Super Wi-Fi. The coverage performance is $72.6 \%$ lower than the first coverage study of TETRA in Fig. 8, 71.2\% lower than the first coverage study of UHF in Fig. 9 and 69.6\% lower than the first coverage study of Super Wi-Fi in Fig. 10. This numerical value satisfies neither the target signal strength nor the target coverage in Table 2. The fringe areas of less than $-85 \mathrm{dBm}$ and the dead spots of less than $-100 \mathrm{dBm}$ were observed across the entire area, except around the Wi-Fi antenna (2.4GHz). In particular, the stern, which was far from the antenna, had a broad dead spot.
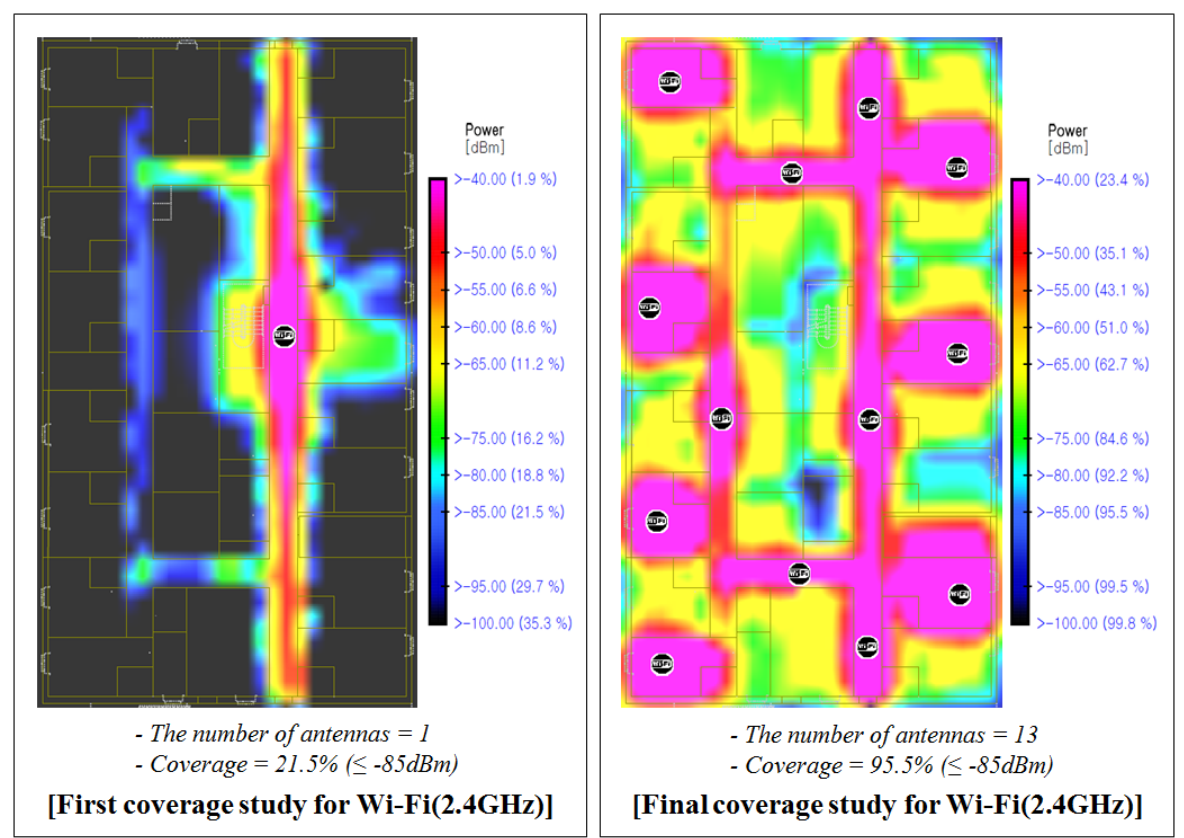

Fig. 11. Comparison of coverage study of Wi-Fi(2.4GHz)

The coverage in the final study for Wi-Fi $(2.4 \mathrm{GHz})$ is $95.5 \%$ when the signal strength exceeds $-85 \mathrm{dBm}$, which is the target signal strength of the fringe area. This numerical value satisfies all the creteria in Table 2 with thirteen Wi-Fi $(2.4 \mathrm{GHz})$ antennas and can eliminate the fringe areas and dead spots in the working areas.

Fig. 12 shows the first Wi-Fi (5GHz) coverage study results. The coverage of the Wi-Fi (5GHz) in the first coverage study is $17.0 \%$ when the signal strength is $-85 \mathrm{dBm}$, which is the target signal strength of the fringe area. The performance of coverage is $20.9 \%$ lower than the first coverage study of Wi-Fi $(2.4 \mathrm{GHz})$ in Fig. 11. The coverage of the frequency band in Table 4 is the lowest of the first coverage study results: $77.2 \%$ lower than UHF and $76.0 \%$ lower than Super Wi-Fi. This numerical value satisfies neither the target signal strength nor the target coverage in Table 2. The fringe areas of less than $-85 \mathrm{dBm}$ and the dead spots of less than $-100 \mathrm{dBm}$ were observed across the entire area, except around the Wi-Fi antenna (5GHz). In particular, the dead spots were wider than the fringe areas throughout the entire area. 

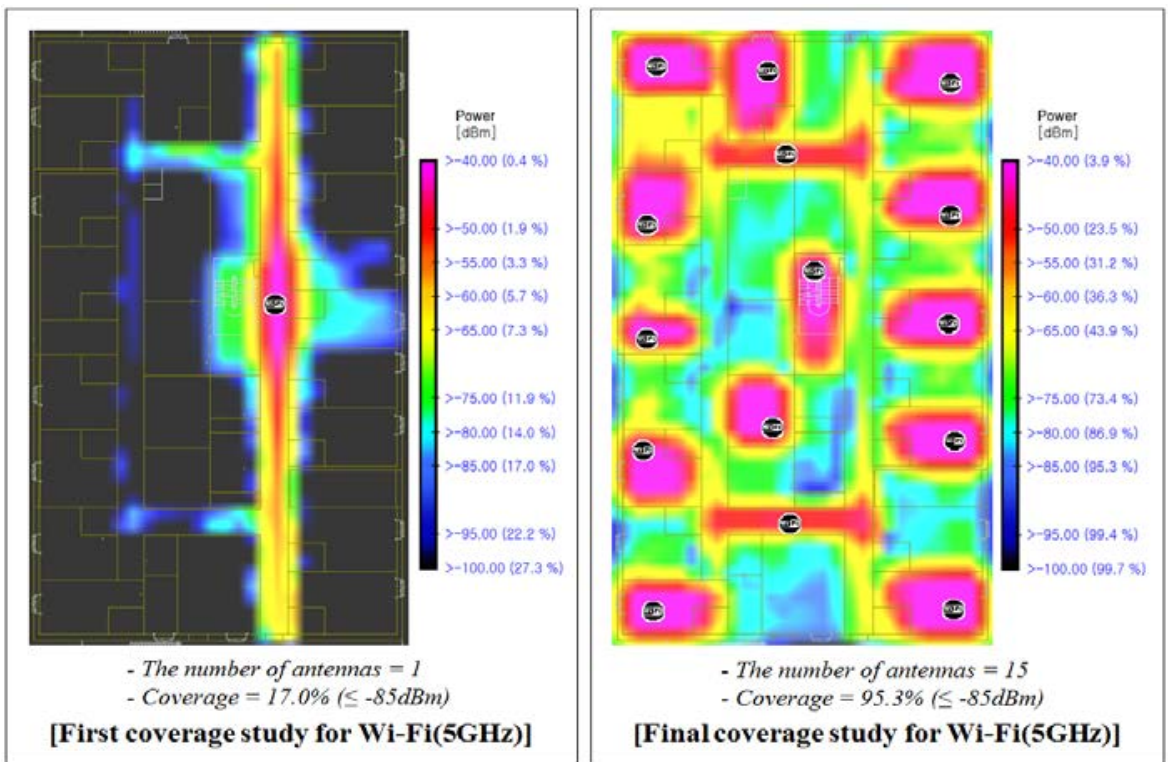

Fig. 12. Comparison of coverage study of Wi-Fi(5GHz)

The coverage in the final study of Wi-Fi (5GHz) is $95.3 \%$ when the signal strength is higher than $-85 \mathrm{dBm}$, which is the target signal strength of the fringe area. This numerical value satisfies all the creteria in Table 2 with fifteen Wi-Fi $(2.4 \mathrm{GHz})$ antennas and can eliminate the fringe areas and dead spots in the working areas.

Fig. 13 compares the target signal strength per frequency band and the number of antennas that satisfy the target coverage. TETRA, UHF and Super Wi-Fi were able to reach the target coverage with two antennas, whereas Wi-Fi $(2.4 \mathrm{GHz})$ and Wi-Fi $(5 \mathrm{GHz})$ required thirteen and fifteen antennas, respectively. The higher the frequency band, the larger the number of antennas required to satisfy the target signal strength and the target coverage.

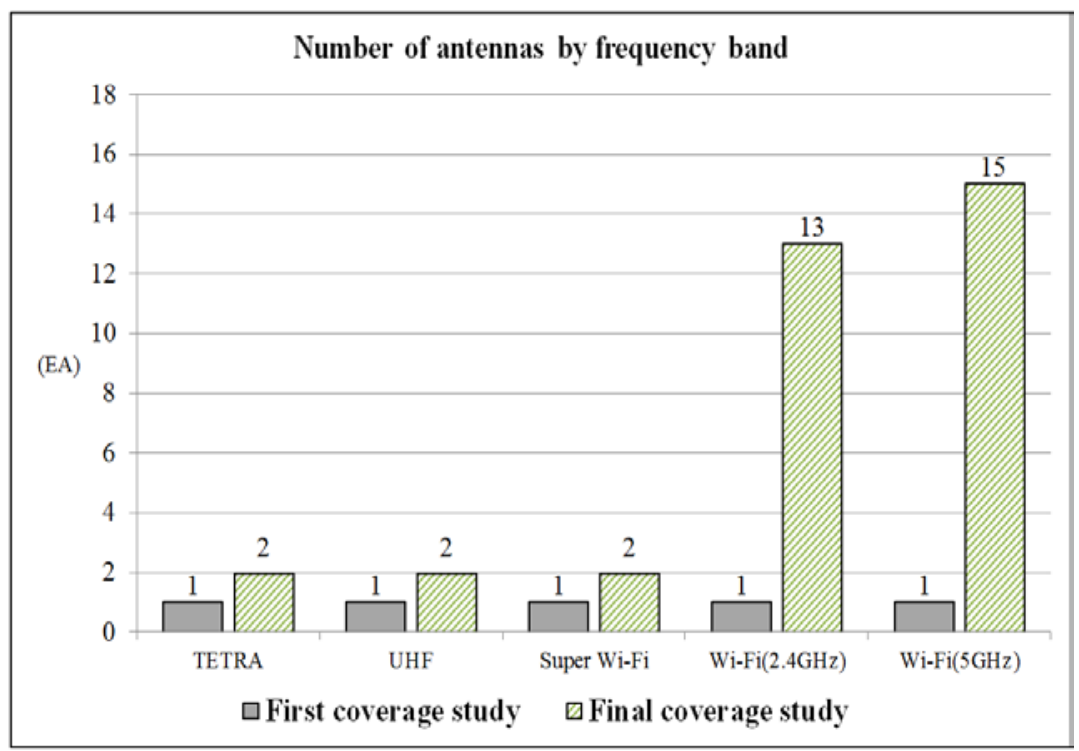

Fig. 13. Number of antennas by frequency band 
Fig. 14 compares the coverage per frequency band between the first and the final coverage studies. In the first coverage study using the same one antenna, a difference of coverage by frequency band was confirmed. The coverage of TETRA, UHF, and Super Wi-Fi, which used the $\mathrm{MHz}$ bands, averaged $74.6 \%$, whereas the coverage of Wi-Fi using the $\mathrm{GHz}$ band averaged $19.3 \%$. The higher the frequency band, the lower the coverage of antennas.

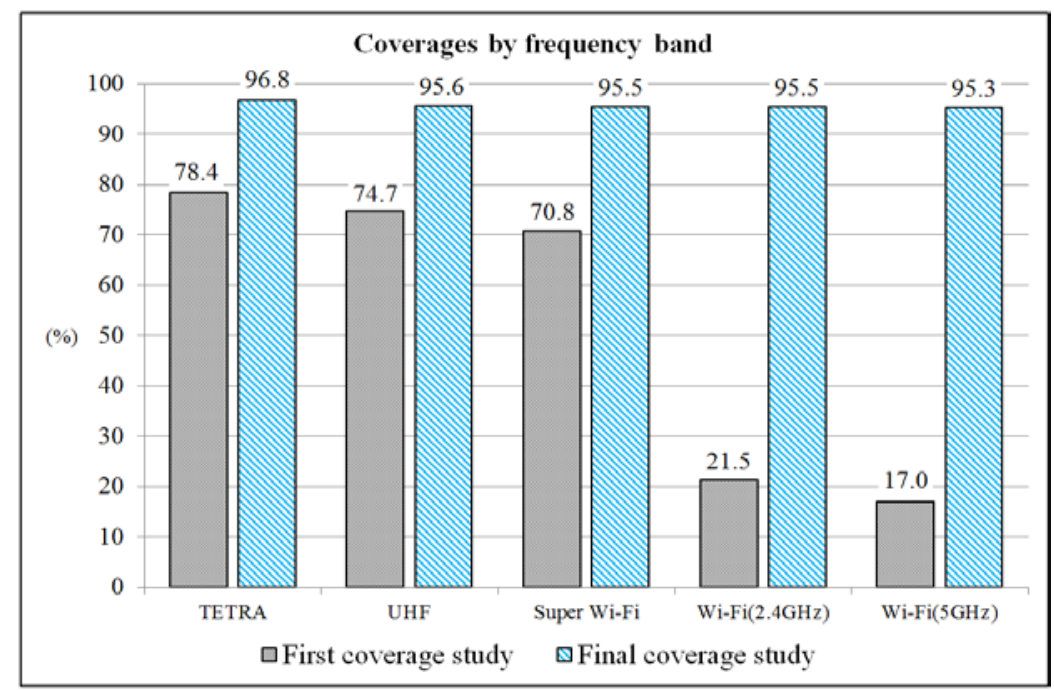

Fig. 14. Coverage by frequency band

Based on the coverage study results, this chapter demonstrates that implementing a wireless network using Wi-Fi over $2.4 \mathrm{GHz}$ on board ships results in a waste of resources and costs and is therefore not feasible in terms of effectiveness. On the ship, Super Wi-Fi was 9.7\% lower than TETRA, and its coverage was 5.2\% lower than UHF. However, TETRA, UHF and Super Wi-Fi are able to cover the entire ship with a small number of antennas. Therefore, to satisfy the UHF-based Super Wi-Fi environment proposed in this paper, Super Wi-Fi should be implemented to reach a coverage of 5.2\%, which is insufficient compared to UHF. At this time, UHF should satisfy the target coverage in the same environment as when Super Wi-Fi satisfies the target coverage. On that basis, the experimental findings in this paper substantiate the feasibility of the ship-wide UHF-based Super Wi-Fi wireless network environment.

\section{Experimental Environment and Method for Super Wi-Fi Environment}

Fig. 15 is a diagram of a UHF system installed on a ship. The fixed base stations are excluded because they do not affect the coverage or overall system configuration. Whip and spot antennas are deployed on the top and hull side of the ship, respectively. The frequencies of the whip and spot antennas ranged from $450 \mathrm{MHz}$ to $470 \mathrm{MHz}$ [28][29].

Leaky antennas with a wide range of frequencies between $30 \mathrm{MHz}$ and $980 \mathrm{MHz}$ were deployed when the space structure was complex and narrow [30]. The installation method is similar to that of the cable installation along the corridor using a cable tray as shown in Fig. 16. 


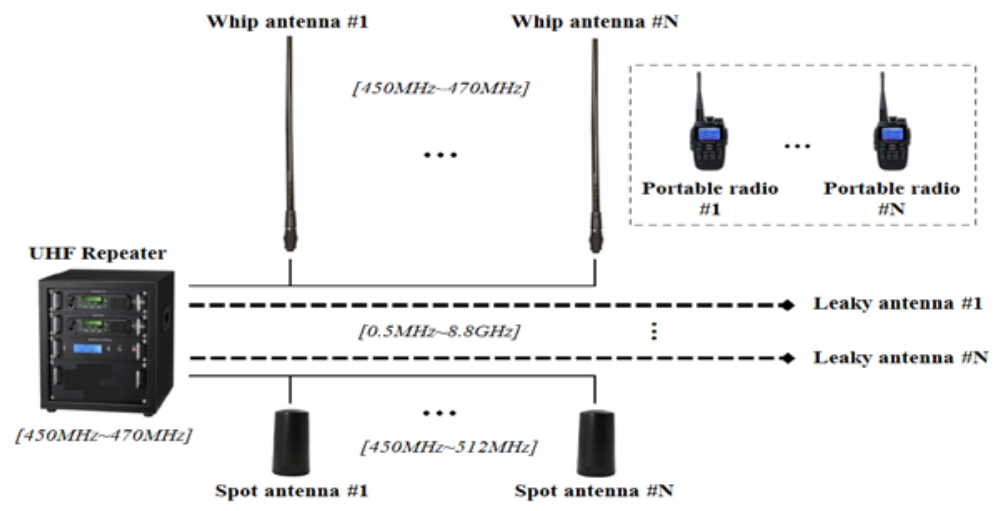

Fig. 15. Diagram for UHF system on a ship

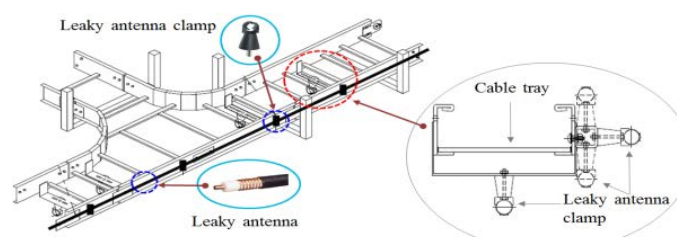

Fig. 16. Installation of leaky antenna on a ship

This paper proposes a method of combining the $450 \mathrm{MHz}$ to $470 \mathrm{MHz}$ UHF frequency band with the $750 \mathrm{MHz}$ to $790 \mathrm{MHz}$ Super Wi-Fi frequency band as shown in Fig. 17. Wide broadband antennas are deployed instead of whip antennas on the top side, while ultra broadband antennas are deployed instead of spot antennas on the hull side. The frequency range for the wide broadband antenna extends from $400 \mathrm{MHz}$ to $800 \mathrm{MHz}$, while that for the ultra broadband antena extends from $300 \mathrm{MHz}$ to $8 \mathrm{GHz}$ [31][32]. The leaky antenna has the same specifications as in Fig. 15. The combiner allows UHF repeaters and Super Wi-Fi base stations to share and use antennas.

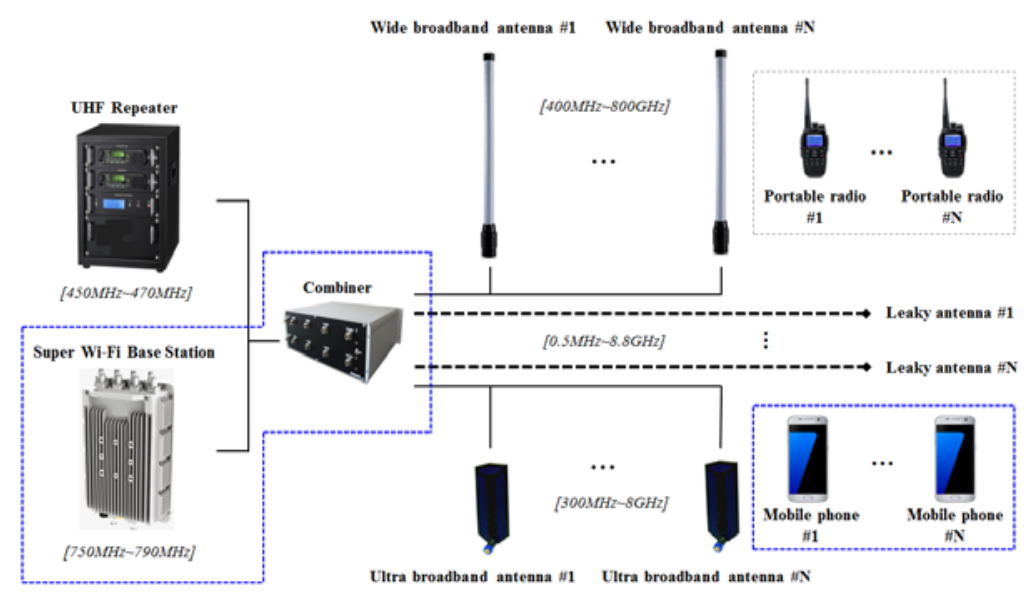

Fig. 17. Combination diagram of Super Wi-Fi and UHF system 
Wide broadband antennas, ultra broadband antennas, and leaky antennas are all included in the frequency range from $450 \mathrm{MHz}$ to $790 \mathrm{MHz}$. We demonstrate through comparative experiments in the next chapter that UHF and Super Wi-Fi can be used simultaneously on board a ship with the same antennas.

The ship's power is produced in the main engine or generator and delivered to the system from the power distribution panel. The ship is configured to have a constant power supply system. In the design stage of the ship, the power consumption for each system is calculated and the supply amount is determined according to the load. The ship has a spare of $20 \%$ to $30 \%$ of the power supply for various variables. Fig. 17 shows a structure to add Super Wi-Fi equipment to the existing UHF system and does not affect the overall power consumption of the ship.

\section{Performance Evaluation}

Experiments were performed on the top side and the hull side of the semi-submersible rig in the order of Super Wi-Fi and UHF. The semi-submersible rig is one of the most complicated ships, and it is difficult to satisfy the conditions in Table 2 when compared to commercial ships. We compared the final coverage study results between UHF and Super Wi-Fi. The UHF system uses portable radios and Super Wi-Fi and assumes that the mobile phone supports the 801.11af standard.

Fig. 18 shows the final coverage study results of Super Wi-Fi on the top side. The coverage is $95.1 \%$ when the signal strength is $-85 \mathrm{dBm}$ which is the target signal strength of the fringe area. This numerical value satisfies all the creteria in Table 2 with three wide broadband antennas and one leaky antenna. There were no fringe areas or dead spots in the working areas on the top side.

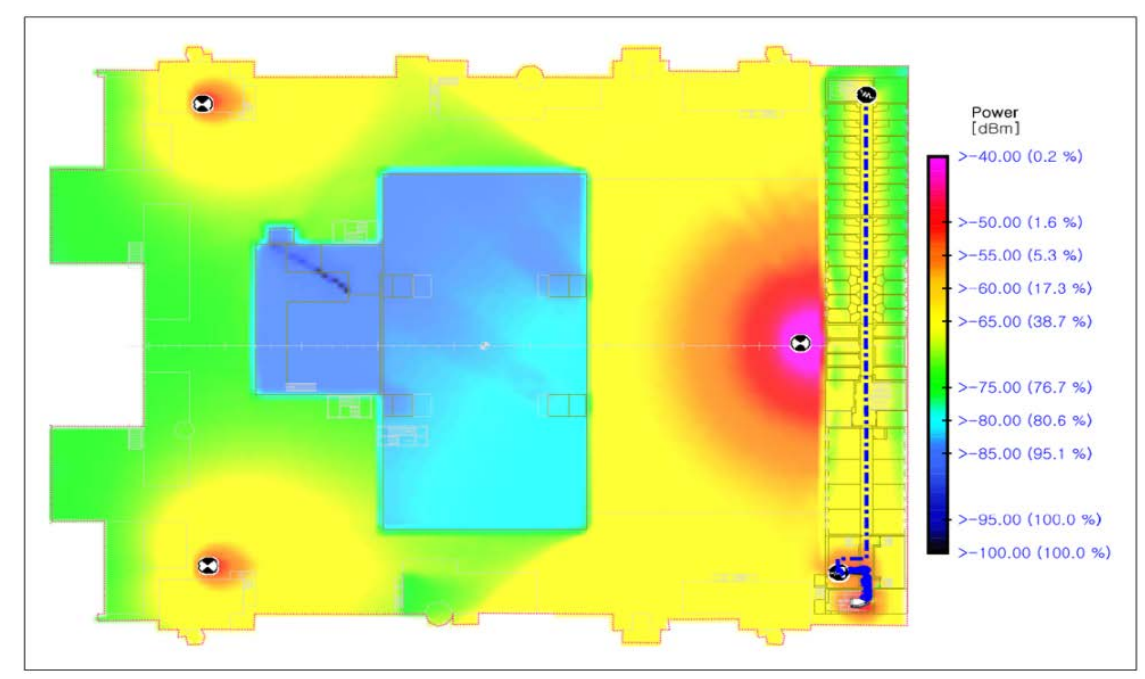

Fig. 18. Final coverage study of Super Wi-Fi at the top side

Fig. 19 shows the final coverage study results of UHF using Super Wi-Fi environment in Fig. 18 as is. Instead of the Super Wi-Fi base station shown in Fig. 17, the UHF repeater generates frequencies between $450 \mathrm{MHz}$ to $470 \mathrm{MHz}$. 
The coverage in the final coverage study of UHF is $98.7 \%$ when the signal strength exceeds $-85 \mathrm{dBm}$, which is the target signal strength of the fringe area. The coverage performance is $3.8 \%$ higher than the final coverage study of Super Wi-Fi in Fig. 18. The analysis indicated that UHF is lower in frequency bands than Super Wi-Fi. There are also no fringe areas and dead spots in working areas on the top side.

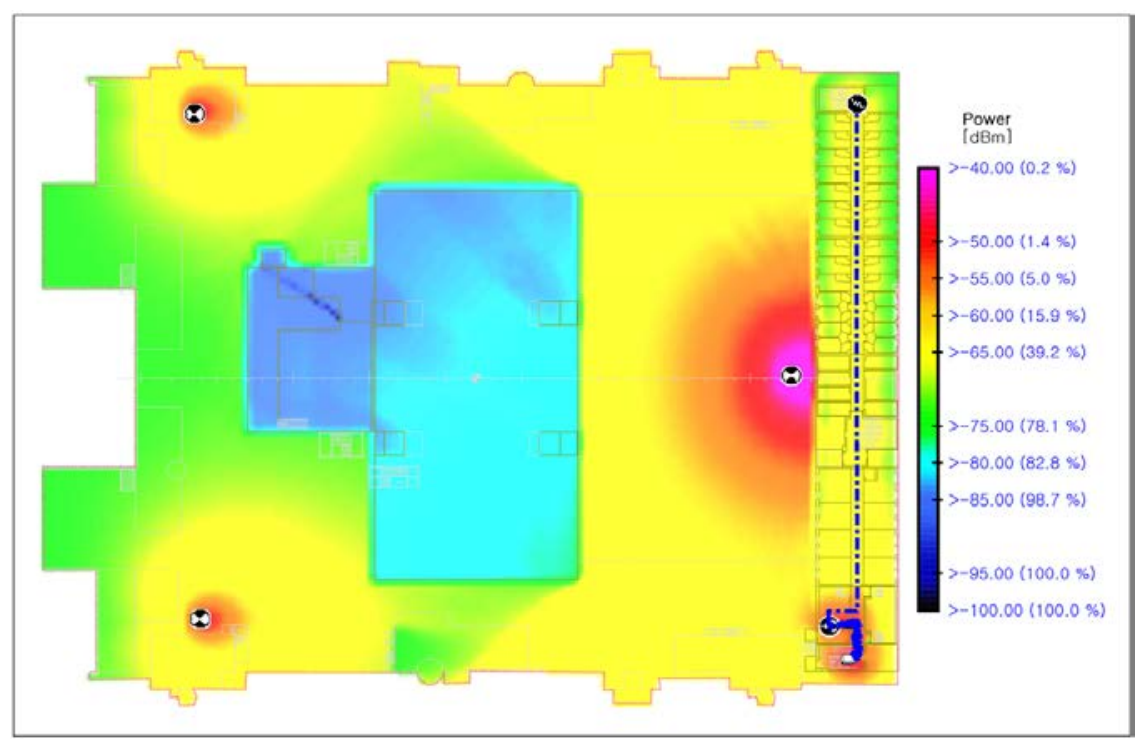

Fig. 19. Final coverage study of UHF at the top side

On the top side, combined with Super Wi-Fi, the established UHF environment satisfies all the criteria in Table 2. The experimental findings on the top side, which is the open space of the ship, confirm that the Super Wi-Fi environment can be established with the UHF system without adding any additional equipment.

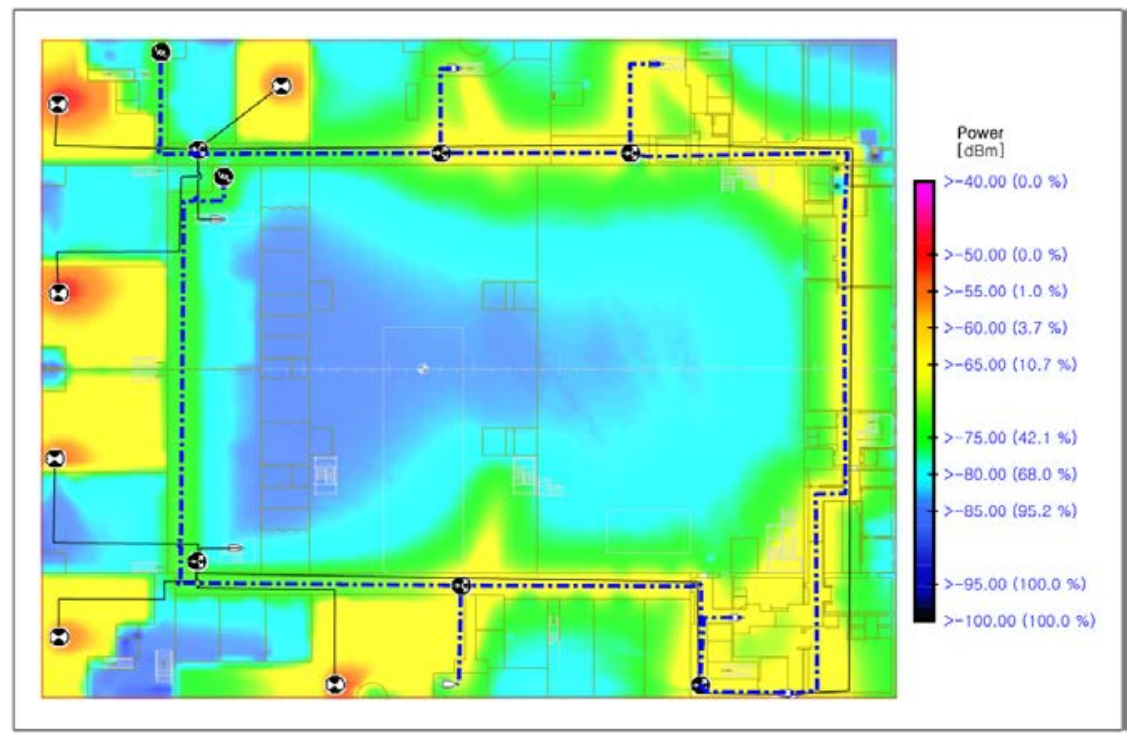

Fig. 20. Final coverage study of Super Wi-Fi on hull side 
Fig. 20 shows the final coverage study results of Super Wi-Fi on the hull side. The coverage is $95.2 \%$ when the signal strength is $-85 \mathrm{dBm}$, which is the target signal strength of the fringe area. This numerical value satisfies all the creteria in Table 2 with six ultra-wideband antennas and two large leaky antennas. The leaky antennas were deployed diverging along the corridor. There are no fringe areas or dead spots in the working areas on the top side.

There are two main reasons why the ultra broadband antennas deployed on the hull side outnumbered those on the top side. First, most of the space except for the bow is composed of a steel wall. As steel has a low transmittance for frequencies, only deploying an antenna in the corridor would not be enough to provide the coverage for the whole area. Second, the water-tight steel door is used to seal the space. The hull side has airtight cells in case of accidents with lots of equipment deployed close to each other, the radio waves are susceptible to interruptions and distortions. The coverage study of the hull side in this paper is based on a worst-case scenario where all the doors are closed.

Fig. 21 shows the final coverage study results of UHF using Super Wi-Fi environment in Fig. 20 as is.



Fig. 21. Final coverage study of UHF on hull side

The coverage in the final coverage study of UHF is $98.5 \%$ when the signal strength is higher than $-85 \mathrm{dBm}$, which is the target signal strength of the fringe area. The coverage performance is 3.5\% higher in comparison to the final coverage study of Super Wi-Fi in Fig. 20. There are no fringe areas and dead spots in working areas on the hull side.

On the hull side, combined with Super Wi-Fi, the established UHF environment satisfied all the criteria in Table 2. The experimental results on the hull side, which accommodates the shielding and airtight cells of the ship, confirmed that a Super Wi-Fi environment can be established with the UHF system alone without adding any additional equipment.

Emerging high-end technologies ensuring both ship safety enhancement and technology development at a minimum cost are crucial for ships. The ship-wide Super Wi-Fi environment can easily implement technologies such as Internet of Things (IoT) and Indoor Positioning 
System (IPS) on board a ship. In this paper, we demonstrate that the wireless network environment is established with Super Wi-Fi throughout the ship using the existing UHF system used on board a ship.

\section{Future Work}

We plan to build on the proposed method for further research in terms of three perspectives. The first research will concern the cognitive radio technology that implements Super Wi-Fi by partitioning the TETRA frequency band. TETRA already supports the technology for both voice and message transmission. The diversity of the wireless network environment is secured for ships. The second research will involve the Indoor Positioning System (IPS) using beacons in the Super Wi-Fi environment of ships. All data on the exact locations of moving objects and people on board a ships are identified and processed in real time. The third and final research will deal with Internet of things (IoT) in the Super Wi-Fi environment of ships. Ships have a wider range of managerial responsibilities than could be handled by a limited number of crew members on duty. In the same vein, it is almost impossible for a person to directly prevent all accidents from occurring on a ship. Yet, all situations occurring on board a ship can be controlled with IoT.

\section{Conclusion}

Until now, the wireless network environment using Wi-Fi on ships has limited scalability, stability, and high costs. Through this experiment, we confirmed the causes of Wi-Fi failures on ships. In today's ships, wireless networks are perceived as an impossible feat and instead all systems are connected to a wired network. Therefore, tasks and management have been classified as separate activities, since real-time management cannot be performed.

The implementation of a wireless network environment for ships will change both the work environment and management methods on ships. Moreover, it will reduce both shipbuilding and maintenance costs and exert some influence on technology development for systems and equipment that have remained unchanged for decades. Despite the foregoing advantages, systems intended for use on land are still being applied to ships. In other words, commercial economic logic has precluded R\&D efforts relevant to ship-specific wireless network technology.

In this paper, we proposed a method of establishing a ship-wide Super Wi-Fi environment leveraging a UHF system, of which the performance has been verified in practice. The proposed ship-wide wireless network environment minimizes the costs for installing a private network.

\section{References}

[1] Norwegian petroleum industry, "Telecom systems," NORSOK Standard, T-001, Edition 4, pp. 8-13, February 2010. Article (CrossRef Link)

[2] Adriana B. Flores, Ryan E. Guerra, Edward W. Knightly Peter Ecclesine and Santosh Pandey, "IEEE 802.11af : A Standard for TV White Space Spectrum Sharing," IEEE Communication Magazine, Vol. 51, Issue. 10, pp.92-100, October 2013. Article (CrossRef Link)

[3] Megha Hanchate, Ravindra Patil, Tillottama Marathe, Sprith Shrivastava, Saurabh Singh and Pradnya Dhivare, "Terrestrial Trunked Radio," in Proc. of Journal of Computing technologies, Volume 1, Issue 4, August 2012. Article (CrossRef Link) 
[4] Norwegian petroleum industry, “Telecom subsystems,” T-100, Edition 4, NORSOK Standard, pp. 27-28, February 2010. Article (CrossRef Link)

[5] Jungwoo Kim, Jeoungkyu Lim and Jooyoung Son, “An Optimal Antenna Placement Scheme for UHF Systems in Ships by a Coverage Study,” in Proc. of International Journal of Applied Engineering Research, Vol. 11, No. 24, pp.11908-11912, December 2016. Article (CrossRef Link)

[6] Demian Lekomtcev and Roman Marsalek, "Comparison of 802.11af and 802.22 standards-physical layer and cognitive functionality,” in Proc. of Journal of Elektrorevue, Vol. 3, No. 2, June 2012. Article (CrossRef Link)

[7] Shanmuga Sundaram B, “A Quantitative analysis of 802.11 ah Wireless Standard,” in Proc. of International Journal of Latest Research in Engineering and Technology, Vol. 2, Issue. 2, pp.26-29, February 2016. Article (CrossRef Link)

[8] Microsoft, “Super Wi-Fi Technologies,” UN Millennium Goal, 2012 Update Report, 2012. Article (CrossRef Link)

[9] IEEE 802.11 Working Group, “IEEE 802.11af Draft 5.0, Amendment 5: TV White Spaces Operation," IEEE, June 2013.

[10] Commission directive(EU) 2015/559, “Amending council directive 96/98/EC on marine equipment,” Official journal of the European Union, April 2015. Article (CrossRef Link)

[11] The sixty-sixth session of the Maritime Safety Committee, "International lift-saving appliance(LSA) code,” Resolution MSC.48(66), Treaty series No.44, IMO, June 1996. Article (CrossRef Link)

[12] Maritime Safety Committee, "Report of the maritime safety committee on its sixty-sixth session," MSC66/24/Add.1, IMO, June 1996. Article (CrossRef Link)

[13] Rules for classification of ships, New buildings, Hull and equipment main class, "Hull equipment and safety,” DNV, Part3, Chapter3, January 2010. Article (CrossRef Link)

[14] Recommendation ITU-R M.1174-2, "Technical characteristics of equipment used for on-board vessel communications in the bands between 450 and $470 \mathrm{MHz}$," ITU, May 2004. Article (CrossRef Link)

[15] Article 52, Special rules relating to the use of frequencies, "Radio Regulations Articles," ITU, Edition of 2012, pp.405-408, May 2004. Article (CrossRef Link)

[16] Jungwoo Kim, Jeoungkyu Lim and Jooyoung Son, “An optimal antenna placement scheme for UHF systems in ships by a coverage study (Abstract)," in Proc. of ISMT 2016, The Korea Society of Marine Engineering, p.77, November 2016. Article (CrossRef Link)

[17] Rohill, "Reliable and Scalable TETRA networks,” TetraNode, White Paper, Issue 1.1, pp.7-12, May 2011. Article (CrossRef Link)

[18] ETSI Project Terrestrial Trunked Radio(TETRA), “Terrestrial Trunked Radio(TETRA); Voice plus Data(V+D); Designers’ guide; Part 1: Overview, technical description and radio aspects,” ETR 300-1, ETSI Technical Report, European Telecommunications Standards Institute(ETSI), p.27, May 1997. Article (CrossRef Link)

[19] ETSI Technical Committee Terrestrial Trunked Radio(TETRA), “Terrestrial Trunked Radio(TETRA); Voice plus Data(V+D); Part 15: TETRA frequency bands, duplex spacings and channel numbering," ETSI TS 100 392-15, v1.4.1, Technical Specification, European Telecommunications Standards Institute(ETSI), p.10, March 2010. Article (CrossRef Link)

[20] Camilla Bonde, Reza Tadayoni and Knud Erik Skouby, "Next Generation Public Safety and Emergency Technologies,” in Proc. of Journal of NBICT, Volume 1, pp.43-72, January 2015. Article (CrossRef Link)

[21] Wikipedia, "Ultra high frequency.” Article (CrossRef Link)

[22] IEEE Aerospace \& Electronic Systems Society, "IEEE standard letter designations for Radar frequency bands,” IEEE standard 521-2002, January 2003. Article (CrossRef Link)

[23] Australian Communications and Media Authority, "Radiocommunications (Citizen Band Radio Stations) Class License 2015,” Federal Register of Legislation, Australian Government, pp. 4-14, June 2015. Article (CrossRef Link) 
[24] Organisation for Economic Co-operation and Development, "Working Party on telecommunication and Information Services Policies," The spectrum dividend: Spectrum Management Issues, Committee for Information, Computer and Communications Policy, DSTI/ICCP/TISP(2006)2/FINAL, p.9, November 2006. Article (CrossRef Link)

[25] National Telecommunications and Information Administration Office of Spectrum Management, "Federal Spectrum Use Summary 30MHz - 3000GHz," NTIA, United States Department of Commerce, pp.14-16, p.40, June 2010. Article (CrossRef Link)

[26] Motorola Solutions, “Two-way Radios.” Article (CrossRef Link)

[27] iBwave, "Solutions for Enterprises.” Article (CrossRef Link)

[28] Comrod, “Marine \& Civil Antennas.” Article (CrossRef Link)

[29] Laird, “Antennas \& Reception Solutions.” Article (CrossRef Link)

[30] Radio Frequency Systems, “Cable solutions.” Article (CrossRef Link)

[31] Star Antenna, “Omni Directional Antennas.” Article (CrossRef Link)

[32] Aaronia AG, “Isotropic Antennas.” Article (CrossRef Link)

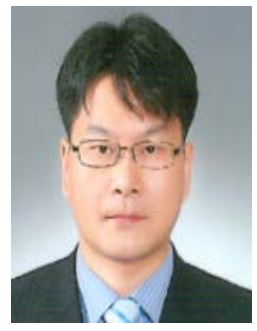

Jungwoo Kim received the M.S degree of computer engineering, Korea Maritime \& Ocean University, Busan, Korea in 2004. He works as an engineer at Hyundai Heavy Industries. His current research interests include telecommunication integration systems in vessels, super $\mathrm{Wi}-\mathrm{Fi}$, offshore engineering and indoor positioning services.

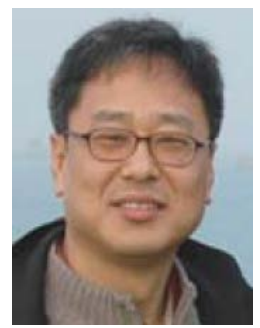

Jooyoung Son received his B.S. degree from Dept. of Computer Science, Seoul National University, Seoul, Korea in 1985, and his M.Eng. and Ph.D. from Dept. of Computer Engineering, Seoul National University in 1993 and 1998, respectively. He has worked for LG Electronics as a senior engineer from 1985 to 1998. He has been a professor at Korea Maritime and Ocean University since 1998. His current research interests include high speed maritime data communication networks, telecommunication integration systems in vessels, maritime self-organizing networks, and indoor positioning services. 